\title{
The Resume Research Literature: Where Have We Been and Where Should We Go Next?
}

\author{
Stephen D. Risavy ${ }^{1}$ \\ ${ }^{1}$ Lazaridis School of Business \& Economics, Wilfrid Laurier University, Waterloo, Ontario, Canada \\ Correspondence: Stephen D. Risavy, Lazaridis School of Business \& Economics, Wilfrid Laurier University, 75 \\ University Avenue West, Waterloo, Ontario, N2L 3C5, Canada. E-mail: srisavy@wlu.ca
}

Received: January 24, 2017

Accepted: February 6, $2017 \quad$ Online Published: February 15, 2017

doi:10.5539/jedp.v7n1p169

URL: http://doi.org/10.5539/jedp.v7n1p169

\begin{abstract}
The resume remains a common selection method used by organizations; however, much of the resume research literature is dated and there is a lack of an organizing framework regarding future resume-related research. Thus, the purpose of the current paper is to provide: (1) a synthesis of the historical empirical research literature through the lens of the advice that has accumulated to date; and (2) an organizing framework containing future research questions that need to be investigated in order to continue moving the literature forward. The current paper will be of use to job applicants, business communication instructors, and researchers.
\end{abstract}

Keywords: resume, cover letter, job applicant, job search, business communication, personnel selection

\section{Introduction}

It has long been established that first impressions have a substantial impact on the interpretation of subsequent information (e.g., Anderson \& Barrios, 1961). In a business context, the first impression of a job applicant has traditionally been made through the resume (e.g., Knouse, 1989; Roderick \& Jelley, 1992; Stanley-Weigand, 1991) and, despite many technological advancements since the initial resume-related publications began to appear in the research literature, the resume remains a common application component (e.g., Catano, Wiesner, \& Hackett, 2016). Thus, the importance of job applicant resumes in terms of business communication cannot be understated; as one earlier resume communication scholar professed: "why teach anything about communicating within the organization unless we teach about how to get into the organization?" (Stull, 1978, p. 8).

Business communication instructors often teach a module on resume and cover letter writing. During this module, it is not uncommon for undergraduate and graduate students to mention the conflicting advice that they have received from the institution's career center, their other instructors, their friends, their family members, the popular press, and so on. Thus, it would be beneficial to have a current resource that synthesizes the extant empirical research literature in order to derive advice for resume and cover letter writing. Without such a resource, the alternative would be for business communication instructors to rely on, at best, a less comprehensive research resource, and, at worst, their own opinions about advice for resume and cover letter writing. The notion of utilizing the empirical research literature in order to derive advice is consonant with the recent and much needed movement towards incorporating evidence-based teaching into management classes (Erez \& Grant, 2014). However, much of the resume research literature is quite dated and a potential barrier to more contemporary and systematic resume-related research is a lack of an organizing framework regarding future research.

Thus, the purpose of the current paper is twofold: (1) the current paper will provide a synthesis of the historical empirical research literature through the lens of the advice that has accumulated to date (i.e., where have we been?); and (2) the current paper will also provide an organizing framework containing future research questions that need to be investigated in order to continue moving the literature forward (i.e., where should we go next?). All of the research studies synthesized in the current paper are derived from empirical data collections from the business communication and human resources management fields, which most often utilized one of the following methodologies: (1) surveying organizational professionals regarding their resume-related preferences; or (2) conducting experimental studies by manipulating resume components. Moreover, the majority of the 
extant research was conducted within the United States and it is noted where studies were conducted outside of the United States.

Research that has demonstrated findings related to information that is not under the control of the applicant or is no longer acceptable to provide based on anti-discrimination legislation (e.g., age, gender, race, marital status, dependents; e.g., Bendick, Jackson, \& Romero, 1996; Bertrand \& Mullainathan, 2004; Dipboye, Arvey, \& Terpstra, 1977; Dipboye, Fromkin, \& Wiback, 1975; Marlowe, Schneider, \& Nelson, 1996; McIntyre, Moberg, \& Posner, 1980; Muchinsky \& Harris, 1977; Oliphant \& Alexander, 1982; Renwick \& Tosi, 1978) is not incorporated into the below discussion. Clearly, it has been established that the following personal information components should not be included in resumes: height, weight, race, religion, birth date, marital status, number of dependents, physical/health status, photographs, and social security number (Hutchinson \& Brefka, 1997). Moreover, consistent with the empirical research-based mandate of the current paper, publications that involve merely opinions without supporting research evidence (e.g., Dittman, 1983; Stanley-Weigand, 1991) are also not incorporated into the below discussion.

The below discussion will involve a comprehensive integration of the most impactful, systematic, and empirical research available in order to see how the following questions have been historically answered in the literature: What information should be included in the resume? How long should the resume be? In what order and style should the resume content be arranged? What is the best available advice for cover letter writing? What other advice is there for resume and cover letter writing? Based on the information and advice that has accumulated to date, a framework for future research needs will be offered. Overall, the work presented in the current paper will be of use to job applicants, business communication instructors, and researchers interested in updating and advancing the resume research literature.

\section{What Information Should Be Included in the Resume?}

Compared with an application form, job applicants can choose what information to include in their resumes. Some of the options for categories to include are: (a) personal information; (b) personal opening, job objective, career objective, and summary of qualifications; (c) education; (d) work experience; (e) references; (f) scholarships, awards, and honors; (g) hobbies, interests, and extracurricular activities; and (h) willingness to relocate and travel. Next, the empirical research literature regarding the information that should be included in the resume for each of the aforementioned categories is reviewed.

\subsection{Personal Information}

A large and well-established body of research has suggested that the applicant's name, address, and phone number should definitely be included in the resume (Hornsby \& Smith, 1995; Hutchinson, 1984; Hutchinson \& Brefka, 1997; Mansfield, 1976; Wells, Spinks, \& Hargrave, 1981). Although not focused on stylistic resume issues, a recent study by Burns, Christiansen, Morris, Periard, and Coaster (2014) has provided support for the inclusion of a school email address over a personal email address as their sample of human resource professionals provided more favorable judgments for resumes that included email addresses containing ".edu". The advice to include a school email address over a personal email address is especially applicable for student applicants and recent graduates but may also have implications for additional applicants. Specifically, future research should address whether more professional email addresses (e.g., givenname.surname@emailprovider.com) are rated more favorably than less professional email addresses.

\subsection{Personal Opening, Job Objective, Career Objective, and Summary of Qualifications}

Although recent research has provided support for the notion that there is no need for a personal opening in a resume (Burns et al., 2014), including a job objective and/or a career objective has traditionally been found to be important information to include in a resume (Harcourt \& Krizan, 1989; Harcourt, Krizan, \& Merrier, 1991; Hornsby \& Smith, 1995; Hutchinson, 1984; Hutchinson \& Brefka, 1997; Schramm \& Dortch, 1991). Harcourt and colleagues' (1991) sample of 212 campus recruiters demonstrated a preference for a career objective over a job objective or a combined career and job objective. However, future research is needed to more conclusively demonstrate the impact of including a career objective, a job objective, or a combined career and job objective especially considering the technological advancements since some of this research was conducted. Lastly, a summary of qualifications may also be important to include in a resume (Harcourt \& Krizan, 1989; Harcourt et al., 1991); however, future research is also needed to determine whether including a summary of qualifications is effective if a career objective, a job objective, or a combined career and job objective has already been included. 
Overall, the best available advice for resume writers is to avoid a personal opening and to instead include an objective or a summary of qualifications.

\subsection{Education}

Both early and more recent resume research agree that resumes should include formal educational qualifications including information regarding the degree or designation as well as the major, minor, and, if applicable, the expected date of graduation (Burns et al., 2014; Feild \& Holley, 1976; Harcourt et al., 1991; Holley, Higgins, \& Speights, 1988; Horn, 1988; Hutchinson, 1984; Hutchinson \& Brefka, 1997; Mansfield, 1976; McNeilly \& Barr, 1997; Schramm \& Dortch, 1991; Spinks \& Wells, 1987, 1993; Su, Lorgnier, Yang, \& Oh, 2015; Wells et al., 1981).

A less intuitive piece of advice for resume writers, based on a national study of practicing Society for Human Resource Management professionals, is to include Grade Point Average (GPA) data including GPA within major and possibly also overall GPA (Ray, Stallard, \& Hunt, 1994). In fact, a convincing body of early and more recent research has supported the inclusion of GPA data in the resume (e.g., Brown \& Campion, 1994; Burns et al., 2014; Campion, 1978; Chen, Huang, \& Lee, 2011; Feild \& Holley, 1976; Harcourt \& Krizan, 1989; McNeilly \& Barr, 1997; Schramm \& Dortch, 1991) and the preference for this type of information increased since the Hutchinson (1984) study (Hutchinson \& Brefka, 1997). Hutchinson and Brefka's (1997) sample of personnel administrators in Fortune 500 organizations demonstrated a preference for the inclusion of GPA information especially when it is high and perhaps even when it is low. In further support of this point, Oliphant and Alexander's (1982) sample of personnel professionals found that resumes including GPA information were rated more favorably than resumes that did not include GPA information when evaluating experimentally manipulated resumes. Moreover, research by Thoms, McMasters, Roberts, and Dombkowski (1999) that also used experimentally manipulated resumes found that resumes with higher GPAs were rated more favorably than resumes with lower GPAs by business professionals.

In further support of the inclusion of academic achievement-related information in the resume, early resume research by Hakel, Dobmeyer, and Dunnette (1970) found that out of scholastic achievement, experience, and personal interests, only scholastic achievement played a substantial role in the evaluation of applicant resumes when their sample of students as well as recruiters from Certified Public Accounting firms assessed the relative impact of each factor. Personal interests (which will be subsequently discussed), even when job-related, did not account for poor scholastic standing (Hakel et al., 1970). The relative importance of scholastic standing was also demonstrated by Dipboye and colleagues (1975) as well as Renwick and Tosi (1978) who demonstrated that field of specialization and graduate degree were more influential factors when making selection decisions based on experimentally manipulated resumes than personal variables, such as gender and marital status.

More recently Cole, Rubin, Feild, and Giles' (2007) sample of 244 experienced recruiters evaluating actual resumes of recent or soon-to-be college graduates demonstrated that strong academic qualifications can account for weaker work experience and extracurricular activities but also that strong work experience and extracurricular activities can account for weaker academic qualifications. Nevertheless, having a strong background in academic performance, work experience, and extracurricular activities is likely to lead to high ratings regarding employment suitability (Cole et al., 2007). Overall, future research should address whether it is most effective to include GPA within major, overall GPA, or both within major and overall GPA. There is also a gap in the research literature in that future studies should address whether the inclusion of GPA information is effective when applicants are applying to non-entry-level jobs.

There is some debate in the resume advice industry regarding the inclusion of high school data but previous research has suggested that this type of information is likely unnecessary and should probably be excluded from resumes (Harcourt \& Krizan, 1989; Hutchinson, 1984; Hutchinson \& Brefka, 1997; Spinks \& Wells, 1987; Wells et al., 1981); that is, unless the high school information is the most recent educational experience that the applicant possesses (Hornsby \& Smith, 1995). Harcourt and colleagues (1991) found that information regarding high school GPA, graduation date, and awards was not preferred by their sample of campus recruiters.

Some earlier resume research of the 500 largest corporations in the United States as listed in the Fortune directory has indicated a preference for the inclusion of the major source of financing during college or university to be listed in the resume (Wells et al., 1981). However, Mansfield (1976) found that 54\% of her sample of Fortune 500 company officials indicated that the major source of financing formal education is of little or no importance. In more recent research, the source of financing while in school was found to be only somewhat important by Hutchinson and Brefka (1997) and to be decreasing in importance since the Hutchinson 
(1984) study. Although it would appear that the major source of financing during college or university is not very important information to include in the resume, future research should update this literature and confirm whether a more effective strategy is to note the major source of financing during college or university or to not mention this information.

Regarding the possible inclusion of class projects and relevant coursework, there have been conflicting findings based on applicant experience and the functional areas in which applicants are applying for jobs (Charney \& Rayman, 1989; Charney, Rayman, \& Ferreira-Buckley, 1992). Nevertheless, some research assessing business professionals has provided support for the inclusion of coursework compared with no coursework being listed (Thoms et al., 1999). Overall, future research is needed in order to update this area of research and to determine whether resumes including class projects and coursework are in fact more effective than resumes that do not include this information.

\subsection{Work Experience}

A primary inclusion for the resume is the work experience section and applicants should include information regarding previous employers, the dates in which they worked for each employer, their job title at each previous employer, and whether each job was part- or full-time (Feild \& Holley, 1976; Harcourt \& Krizan, 1989; Harcourt et al., 1991; Holley et al., 1988; Horn, 1988; Hutchinson, 1984; Hutchinson \& Brefka, 1997; Mansfield, 1976; McNeilly \& Barr, 1997; Schramm \& Dortch, 1991; Spinks \& Wells, 1987, 1993; Wells et al., 1981). Moreover, it has been shown that it is important to include work experience information even if the previous experience is unrelated to the job in question (Hornsby \& Smith, 1995; Sulastri, Handoko, \& Janssens, 2015).

\subsection{References}

Regarding the inclusion of references in resumes, previous studies have indicated that the inclusion of references in a resume or at other initial screening stages is of little or no importance (Horn, 1988; Hutchinson, 1984; Hutchinson \& Brefka, 1997; Ray et al., 1994; Schramm \& Dortch, 1991); nor is it necessary to state that references are available upon request (e.g., Schramm \& Dortch, 1991). However, it is worth noting that Harcourt and Krizan's (1989) sample of Fortune 500 personnel administrators as well as business communication instructors demonstrated an increasing desire for references to be included in the resume since the Hutchinson (1984) study and that Harcourt and colleagues (1991) found a preference for the inclusion of a "references available on request" (p. 269) statement. Moreover, other research has also advocated for the inclusion of references in the resume (e.g., Spinks \& Wells, 1987; Wells et al., 1981). Thus, future research should address whether resumes prepared with or without references or the verbiage "references available upon request" are rated more favorably and this is an especially important area for research to update as the research cited above is somewhat dated. Regardless, the inclusion of personal as opposed to professional references in the resume should be avoided (e.g., Harcourt et al., 1991).

\subsection{Scholarships, Awards, and Honors}

Previous research has provided support for the inclusion of a list of scholarships, awards, and honors in resumes (Burns et al., 2014; Campion, 1978; Hornsby \& Smith, 1995; Hutchinson \& Brefka, 1997; Mansfield, 1976; Schramm \& Dortch, 1991; Wells et al., 1981). Moreover, the preference for the inclusion of awards received on resumes increased in importance since the Hutchinson (1984) study (Hutchinson \& Brefka, 1997).

\subsection{Hobbies, Interests, and Extracurricular Activities}

Despite the evidence in support of the inclusion of special skills and job aptitudes in resumes (e.g., languages, software; Harcourt \& Krizan, 1989; Harcourt et al., 1991; Hutchinson, 1984; Wells et al., 1981), an ongoing debate in the literature pertains to the inclusion of categories, such as hobbies and interests. In early resume research (Mansfield, 1976), less than 50\% of the company officials surveyed from the Fortune 500 Largest Industrial Corporations preferred information pertaining to non-job-related factors, such as hobbies and recreational interests to be included in the resume. Pibal (1985) also found that basic resume content (e.g., work experience, education) was ranked more highly than personal items. Harcourt and Krizan (1989) demonstrated that since the Hutchinson (1984) study, preferences of personnel administrators of Fortune 500 companies for the inclusion of hobbies and outside interests declined. Lastly, Hutchinson and Brefka (1997) provided evidence that the listing of memberships in college clubs, fraternities, and sororities as well as hobbies and interests are not important to include in the resume. Nevertheless, recent research by Burns and colleagues (2014) did provide evidence that would support the inclusion of social activities and hobbies (but not recreational sport activities). 
Thus, future research is needed in order to determine the effectiveness of including hobbies and interests in resumes.

Conversely, there does appear to be a consensus regarding the benefits of including extracurricular activities in resumes (Burns et al., 2014; Chen et al., 2011; Schramm \& Dortch, 1991; Rubin, Bommer, \& Baldwin, 2002). Brown and Campion's (1994) sample of recruiters found an advantage for applicant resumes that included extracurricular activities so long as they were not associated with recreational sports or fraternity involvement, which helps to underscore the importance of including job-related information in all sections of the resume. Memberships in professional organizations and associations have been shown to be beneficial extracurricular activities to include in resumes (e.g., Campion, 1978; Harcourt \& Krizan, 1989; Harcourt et al., 1991). The study by Brown and Campion (1994) also helps to demonstrate the progression of earlier resume research as Campion (1978) originally found a benefit associated with including fraternity and sorority membership in the resume; a conclusion that had clearly changed in his subsequent publication (i.e., Brown \& Campion, 1994). There is also some evidence to support the advice that resume writers should exclude church involvement from their resumes (Harcourt \& Krizan, 1989; Harcourt et al., 1991); moreover, other scholars have cautioned that religious, political, ethnic, or sociocultural affiliations may influence the decisions made by recruiters (Derous \& Ryan, 2012).

Nemanick and Clark's (2002) sample of undergraduate students rating experimentally manipulated resumes found that applicants holding numerous (i.e., five) extracurricular leadership positions were judged very favorably and this was especially the case for those applicants with both career-related and social extracurricular activities. For applicants holding two leadership positions or five non-leadership positions, they were judged more favorably when they included career-related as opposed to social extracurricular activities (Nemanick \& Clark, 2002). These findings help to supplement the research conducted by Blackburn-Brockman and Belanger (2001), which involved a sample of 105 Certified Professional Accountant recruiters indicating a benefit of elaborating upon extracurricular activities, professional accomplishments, and community service that reflect leadership, commitment, involvement, and balance but only when the applicants had outstanding grades and previous work experience.

Overall, extracurricular activities have been shown to be important to include in applicant resumes. However, resumes that elaborated upon work experience as opposed to extracurricular activities were still more likely to be perceived as qualified and employable; thus, more space in the resume should be dedicated to providing work experience details as opposed to educational experience or extracurricular activity details (McNeilly \& Barr, 1997). Based on the fact that most of the aforementioned research has focused on student and recent graduate applicants, future studies should seek to update this body of research and assess whether extracurricular activities should be included in resumes for non-student applicants and non-recent graduate applicants.

\subsection{Willingness to Relocate and Travel}

Some empirical research literature has recommended the inclusion of information pertaining to an applicant's willingness or lack of willingness to relocate and travel in the resume (Harcourt \& Krizan, 1989; Harcourt et al., 1991; Hutchinson, 1984; Wells et al., 1981). Moreover, willingness to relocate and travel information was found to be even more important to include since the Hutchinson (1984) study (Hutchinson \& Brefka, 1997). However, it is a viable future research question to assess whether information regarding willingness to relocate and travel would be better included in the cover letter as opposed to in the resume. Moreover, based on the time that has passed since these initial studies have been conducted, future research efforts should seek to corroborate these findings in a more contemporary context as the business world continues to become more global.

\section{How Long Should the Resume Be?}

Once applicants have determined what information to include in their resumes, advice is needed regarding the most effective resume length. In the aforementioned study by Mansfield (1976), the company officials responding to her survey indicated a preference for a concise one- to two-page resume. The advice regarding not exceeding two pages for resumes has been a consistent finding in the literature over time (e.g., Feild \& Holley, 1976; Harcourt \& Krizan, 1989; Harcourt et al., 1991; Horn, 1988; Hornsby \& Smith, 1995; Schramm \& Dortch, 1991; Thoms et al., 1999). For example, previous research has demonstrated that one- to two-page resumes are more desirable than three-page resumes (Spinks \& Wells, 1987; Wells et al., 1981).

However, some research as well as the resume advice industry in general has at times advocated for a one- over a two-page resume (e.g., Spinks \& Wells, 1993). Moreover, 80\% of the recruiters surveyed by McDowell (1987) 
believed that resumes should be one page in length. On the contrary, two-page resumes were ranked more favorably by accounting firm recruiters than one-page resumes for accounting majors with strong school and work credentials when applying to professional accounting firms (Blackburn-Brockman \& Belanger, 2001). Thus, although applicants should ensure that their resumes do not exceed two pages, future research should continue to pursue the quest for determining the most effective resume length. For example, no extant research has addressed whether two-page versus one-and-a-half-page resumes are more effective.

\section{In What Order and Style Should the Resume Content Be Arranged?}

An early study of professional recruiters assessing experimentally manipulated resumes by Penrose (1973) found no order effects when varying resume components while holding content constant, such as if major qualifications appeared first or last in the resume. Conversely, subsequent research by Schramm and Dortch (1991) found that more than $80 \%$ of their sample of on-campus recruiters reported that the order in which resume items appeared was of some degree of importance. This section will discuss the historical advice for applicants to consider regarding resume order, overall format, and other stylistic issues.

\subsection{Resume Order}

A common finding throughout various resume research endeavors is that the more traditional sequencing of resume content (e.g., opening with personal information, followed by education, experience, and then references; Wells et al., 1981) is preferred. Other, more recent research has corroborated the notion that education should be the first category on the resume and that experience should be the second category on the resume (Burns et al., 2014; Spinks \& Wells, 1987). However, future research should assess the efficacy of this ordering for non-student applicants and non-recent graduate applicants as it could be reasoned that for these applicants, the work experience section is their greatest asset and thus, should precede the education section.

\subsection{Overall Resume Format}

Regarding resume format, there is a strong preference for the traditional, standard, historical, chronological format over alternative options (e.g., functional, informal, creative, imaginative, web-based, video-based; Hornsby \& Smith, 1995; Schramm \& Dortch, 1991; Toth, 1993). The aesthetic aspects of a resume likely have a substantial impact on being shortlisted for a job (e.g., Arnulf, Tegner, \& Larssen, 2010; Chen et al., 2011). Specifically, Arnulf and colleagues' (2010) sample of Norwegian professional recruiters and students found that formal resume designs were preferred over more creative (i.e., colored and artistically arranged) designs; in fact, even resumes printed on colored paper ranked higher than the "creative" format. It is interesting to note that this study was conducted in Norway - a country where there are few standardized practices for resume creation - and the findings nevertheless corroborated the effectiveness of the traditional resume format. Schullery, Ickes, and Schullery's (2009) sample of 234 professionals from a wide range of company sizes and industries provided further evidence that there is no need to prepare resumes differently (e.g., so that they can be scanned by electronic devices, such as optical character recognition [OCR] readers).

Research conducted in the Netherlands with a sample of 445 unemployed job applicants has demonstrated that video-based resumes appear to have some benefits regarding applicant perceptions as they are considered by applicants (regardless of their ethnicity) to be fairer than traditional, paper-based resumes (Hiemstra, Derous, Serlie, \& Born, 2012). However, laboratory research using an undergraduate sample suggested that evaluations of applied social skills and mental capabilities of applicants were lower when those evaluations were based solely on video resumes as opposed to when those evaluations were based solely on paper resumes (Waung, Hymes, \& Beatty, 2014). In addition, a follow-up study utilizing a recruiter and student sample demonstrated the ineffectiveness of high levels of self-promotion in video resumes for men and the possible detrimental effects of high levels of self-promotion in video resumes for women (Waung, Hymes, Beatty, \& McAuslan, 2015). From an applicant perspective, caution needs to be exercised when it comes to the use of video-based resumes as the aforementioned research suggests that they are also likely to be a less effective format than traditional resumes.

Similarly, some recent research using a hiring manager and human resource professional sample has tentatively advocated for the benefits of adding personality, emotional intelligence, diversity tolerance, and preferred organizational structure information to the standard resume (Wright, Domagalski, \& Collins, 2011); however, caution should be taken with regards to this conclusion as well based on the aforementioned research advocating for the traditional resume format (e.g., Arnulf et al., 2010). Nevertheless, future research comparing the method advocated by Wright and colleagues (2011) with the traditional resume format is needed. Also, determining whether information pertaining to personality, emotional intelligence, diversity tolerance, and preferred 
organizational structure is more effective when it is included in the resume or in the cover letter is another fruitful avenue for future research.

\subsection{Other Resume Stylistic Issues}

Regarding other resume stylistic issues, an early study by Helwig (1985) provided support for the importance of being concise and using traditional, short, bullet point resumes over highly elaborated, lengthy, narrative resumes. Subsequent research has provided further evidence supporting the advice to avoid a paragraph presentation style in the resume (Horn, 1988) as well as findings in support of using action verbs and bullets in addition to bolding in the resume (e.g., Burns et al., 2014; Hornsby \& Smith, 1995). Being specific when possible, avoiding vague assertions (e.g., Oliphant \& Alexander, 1982; Stephens, Watt, \& Hobbs, 1979), providing details regarding jobs, skills, education, and experiences (Burns et al., 2014), and writing in the third person as opposed to the first person (Horn, 1988) are other stylistic recommendations that should likely be followed by applicants. Aligning job experience dates on the left- or right-hand side of the page (i.e., not with the job experience information itself) and ensuring that the margins are of a standard size should also help with the stylistic and aesthetic issues that can plague resumes (Burns et al., 2014). Lastly, regarding resume color, white or ivory documents are preferred over colored documents (Arnulf et al., 2010; Bird \& Puglisi, 1986; Penrose, 1984; Schramm \& Dortch, 1991; Stephens et al., 1979). Gold and light blue were shown to be the least preferred resume colors in the aforementioned Schramm and Dortch (1991) study.

\section{What Is the Best Available Advice for Cover Letter Writing?}

Cover letters-formerly referred to as transmittal letters (e.g., Weeks, 1975) or letters of application (e.g., Spinks \& Wells, 1987; Welch, 1986) - are often included along with resumes in the initial job application process. A convincing body of literature has developed over time supporting the preference or expectation of a cover letter to be included along with a resume as opposed to a resume being submitted without a cover letter (DeKay, 2006; Harcourt et al., 1991; Hornsby \& Smith, 1995; Schullery et al., 1999; Spinks \& Wells, 1987; Wells et al., 1981).

Cover letters are perhaps most effective when they: (a) are written in the first person as opposed to the third person; (b) are customized for each application; (c) indicate the job for which the applicant is applying; (d) demonstrate knowledge regarding the potential employer, such as reasons why the applicant is interested in the particular job and company; (e) demonstrate the applicant's ability to contribute to the job in question, such as through an explanation of how the applicant's education and experience fit the job requirements; and (f) close by making a request for a personal interview (Horn, 1988; Mansfield, 1976; Spinks \& Wells, 1987; Wells et al., 1981). Furthermore, there appears to be a general preference for avoiding redundancies with the information included in the resume (Mansfield, 1976) as well as for avoiding vague statements through the use of specificity and precision (Spinks \& Wells, 1987; Wells et al., 1981). Regarding length, cover letters should be no longer than one page (Horn, 1988) and should contain less than four paragraphs (Augustin, 1991).

Overall, the cover letter appears to be an important opportunity for applicants to include relevant and unique items that are not included in the resume. However, much less empirical research has been conducted on cover letters compared with resumes and based on the benefits to applicants associated with including cover letters along with their resumes (DeKay, 2006; Harcourt et al., 1991; Hornsby \& Smith, 1995; Schullery et al., 1999; Spinks \& Wells, 1987; Wells et al., 1981) as well as the fact that many of the studies in this area are now dated, there is a need for subsequent research in this area. For example, Augustin (1991) assumed that a format containing only paragraphs should be used in cover letters but based on the short amount of time that recruiters likely spend reviewing cover letters, future research should investigate whether cover letters written in a paragraph format are in fact more effective than cover letters written in a combined paragraph and bullet point format or in a combined paragraph and table format. The nature of the job in question may also suggest that in some cases a more assertive cover letter should be written (e.g., for jobs in high-pressured sales environments); however, Horn (1988) demonstrated that a realistic attitude and modest confidence towards an applicant's own job-related qualifications are appreciated (especially in the cover letter). Regardless, future research should seek to identify the appropriate level of assertiveness to include in application materials.

\section{What Other Advice Is There for Resume and Cover Letter Writing?}

The synthesis of information presented in the current paper will conclude with further advice from the empirical research literature regarding resume and cover letter writing that did not fit under one of the aforementioned headings; specifically, this section will address: (a) grammar, spelling, word choice, punctuation, neatness, and professional appearance; (b) impression management; and (c) other additional advice. 


\subsection{Grammar, Spelling, Word Choice, Punctuation, Neatness, and Professional Appearance}

It is of the utmost importance to have correct and error-free grammar, spelling, word choice, and punctuation as well as overall neatness and professional appearance in resumes and cover letters (Burns et al., 2014; Charney \& Rayman, 1989; Charney et al., 1992; Culwell-Block \& Sellers, 1994; Horn, 1988; Hornsby \& Smith, 1995; Mansfield, 1976; McDowell, 1987; Schramm \& Dortch, 1991; Spinks \& Wells, 1987, 1993; Stephens et al., 1979; Wells et al., 1981). In fact, previous studies have demonstrated that resume and cover letter communication proficiency is at least as important as (Horn, 1988) if not more important than (Charney \& Rayman, 1989) technical competence, relevant work experience, and qualifications. For example, resumes without errors but with less relevant work experience were rated more highly than resumes with errors but with highly relevant work experience by campus recruiters that typically employ mechanical engineers (Charney \& Rayman, 1989). In a subsequent study, Charney and colleagues (1992) demonstrated that undergraduate business students evaluating marketing resumes do not penalize or distinguish between error-laden compared with error-free resumes; conversely, they found that the undergraduate students did distinguish between error-free and error-laden resumes when evaluating engineering resumes, but not to the same extent as actual engineering recruiters. Thus, perhaps one of the reasons why student applicants may have grammatical, spelling, word choice, punctuation, neatness, and professional appearance issues in their resumes and cover letters is that they typically underestimate the impact that these errors have on the evaluation of their application materials.

\subsection{Impression Management}

Submitting an application is in essence an exercise in impression management (Schlenker, 1980) as the applicant is hoping to control the impression that is formed by the recruiter of the applicant's competence, motivation, and experience. However, lower perceptions of applicant likability, truthfulness, and employability were found when impression management was used in resumes and cover letters (the effect was especially strong for resumes and the only positive was in terms of enhanced perceptions of applicant self-confidence as rated by the sample of executive MBA students; Knouse, Giacalone, \& Pollard, 1988). Conversely, a subsequent study by Knouse (1994) utilizing a sample of Chamber of Commerce members demonstrated more favorable perceptions of applicant interpersonal skill, overall impressiveness, and hireability in addition to self-confidence (but desire to further verify applicant background was also rated more highly) when impression management was used. Nevertheless, as noted by Knouse (1994), the specific type of impression management technique being utilized might help to explain the discrepancy between these two studies.

Specifically, tactics associated with ingratiation and the exaggeration of personal traits and accomplishments (Knouse et al., 1988) are likely to be less effective than self-descriptive statements (e.g., examples and descriptions of favorable education- and job-related accomplishments) that clarify and enhance credentials in a reasonable and not overly exaggerated manner (Knouse, 1994). It appears that this latter set of impression management tactics are consistent with the aforementioned findings regarding appropriately elaborating upon and providing sufficient levels of detail regarding resume aspects, such as education, work experience, and extracurricular activities (Blackburn-Brockman \& Belanger, 2001; McNeilly \& Barr, 1997).

Overall, elaborating upon accomplishment statements as opposed to making unwarranted and exaggerated self-descriptive statements appears to be beneficial advice for applicants. In further support of this, Thoms and colleagues (1999) demonstrated that including accomplishment statements (e.g., "not one customer complaint in two years"; p. 347) resulted in more favorable ratings than resumes that do not contain these types of statements. Additional research utilizing a sample of managers and human resource consultants has specified the importance of including between two to six job competency statements (i.e., descriptions of knowledge, skill, ability, and other characteristics) in order to improve the hiring manager's impression of the applicant (Bright \& Hutton, 2000).

Regarding applicants choosing to use video-based resumes (which, as discussed above, is likely to be a less effective resume format than the traditional resume format), they should be further cautioned regarding the use of impression management tactics in video-based resumes. This is especially the case when the impression management tactic used is of high intensity (e.g., "While working on this project I was told that I was an ideal [emphasis added] example to the newer interns due to my positive attitude and unfailing [emphasis added] professionalism"; Waung et al., 2015, p. 349) as high levels of self-promotion in video resumes were ineffective and this negative impact was strongest for male applicants (Waung et al., 2015). 


\subsection{Other Additional Advice}

Here are a few final additional pieces of resume-related advice from the empirical research literature: applicants should: (a) print and bring copies of their resume to the interview (e.g., Spinks \& Wells, 1993); (b) take the time and effort to customize their resumes specifically for each job that is desired (Brown \& Campion, 1994; Holley et al., 1988; Hornsby \& Smith, 1995); and (c) deliver their resumes to potential employers electronically — either via email (with the resume included as an attachment as opposed to pasted into the body of the email) or via the company's website; Schullery et al., 1999). Overall, many additional research questions will emerge regarding resume and cover letter writing especially considering the technological advancements since many of the studies cited in the current paper were conducted; for example, have the substantial technological advancements changed the way that employers prefer to receive resumes? Is it more effective to electronically submit resumes in an Adobe PDF file format or in a Word document file format? Is it more effective to electronically submit a separate resume file and a separate cover letter file or should one file containing both the resume and the cover letter be submitted? Should the cover letter be pasted into the email itself and the resume attached to the email or should the resume and cover letter be attached to the email and something else be written in the body of the email?

\section{Discussion}

Although some scholars have argued that "there are few fixed rules about resumes" (Dittman, 1983, p. 16), in some cases in the current paper, relatively consistent results were found across various research methodologies, geographic locations, and time periods. These more consistent results have been summarized in Table 1 and have resulted in a synthesis of the historical empirical research literature through the lens of the advice that has accumulated to date. As noted at the outset and throughout the current paper, technological and other advancements have changed the business landscape as a whole; thus, the premise of the current paper was to provide an organizing framework containing future research questions that need to be investigated in order to continue moving the literature forward. In addition to the recent technological and other advancements since some of the studies were published, discrepancies across studies as well as other ideas that require future research efforts were also noted throughout the current paper and the resulting framework for organizing future research has been summarized in Table 2 .

Table 1. Where have we been? Historical advice for resume and cover letter writing

\begin{tabular}{|c|c|c|}
\hline Area & Advice & Relevant Citation(s) \\
\hline General & $\begin{array}{ll}\text { Do not include: } \\
\text { - } & \text { height } \\
\text { - } & \text { weight } \\
\text { - } & \text { race } \\
\text { - } & \text { religion } \\
\text { - } & \text { birth date } \\
\text { - } & \text { marital status } \\
\text { - } & \text { number of dependents } \\
\text { - } & \text { physical/health status } \\
\text { - } & \text { photographs } \\
\text { - } & \text { social security number }\end{array}$ & Hutchinson and Brefka (1997) \\
\hline Personal Information & $\begin{aligned} \text { Include: } & \\
\text { - } & \text { name } \\
\text { - } & \text { address } \\
\text { - } & \text { phone number } \\
\text { - } & \text { email address }\end{aligned}$ & $\begin{array}{l}\text { Burns et al. (2014) } \\
\text { Hornsby and Smith (1995) } \\
\text { Hutchinson (1984) } \\
\text { Hutchinson and Brefka (1997) } \\
\text { Mansfield (1976) } \\
\text { Wells et al. (1981) }\end{array}$ \\
\hline
\end{tabular}




\begin{tabular}{|c|c|c|}
\hline \multirow{7}{*}{$\begin{array}{l}\text { Personal Opening, } \\
\text { Job Objective, Career } \\
\text { Objective, and } \\
\text { Summary of } \\
\text { Qualifications }\end{array}$} & Include: & Burns et al. (2014) \\
\hline & - $\quad$ objective & Harcourt and Krizan (1989) \\
\hline & - $\quad$ summary of qualifications & Harcourt et al. (1991) \\
\hline & & Hornsby and Smith (1995) \\
\hline & Do not include: & Hutchinson (1984) \\
\hline & \multirow[t]{2}{*}{ - $\quad$ personal opening } & Hutchinson and Brefka (1997) \\
\hline & & Schramm and Dortch, 1991 \\
\hline \multirow[t]{20}{*}{ Education } & Include: & Burns et al. (2014) \\
\hline & - degree, designation & Cole et al. (2007) \\
\hline & - major, minor & Feild and Holley (1976) \\
\hline & - $\quad$ expected date of graduation (if applicable) & Hakel et al. (1970) \\
\hline & - $\quad \mathrm{GPA}$ & Harcourt and Krizan (1989) \\
\hline & & Harcourt et al. (1991) \\
\hline & Do not include: & Holley et al. (1988) \\
\hline & \multirow{13}{*}{$\begin{array}{l}\text { - high school GPA, graduation date, and } \\
\text { awards (unless this is the most recent } \\
\text { educational experience that the applicant } \\
\text { possesses) }\end{array}$} & Horn (1988) \\
\hline & & Hornsby and Smith (1995) \\
\hline & & Hutchinson (1984) \\
\hline & & Hutchinson and Brefka (1997) \\
\hline & & Mansfield (1976) \\
\hline & & McNeilly and Barr (1997) \\
\hline & & Oliphant and Alexander (1982) \\
\hline & & Ray et al. (1994) \\
\hline & & Schramm and Dortch (1991) \\
\hline & & Spinks and Wells $(1987,1993)$ \\
\hline & & Su et al. (2015) \\
\hline & & Thoms et al. (1999) \\
\hline & & Wells et al. (1981) \\
\hline \multirow[t]{14}{*}{ Work Experience } & \multirow{14}{*}{$\begin{array}{l}\text { job title } \\
\text { whether each job was part- or full-time }\end{array}$} & Feild and Holley (1976) \\
\hline & & Harcourt and Krizan (1989) \\
\hline & & Harcourt et al. (1991) \\
\hline & & Holley et al. (1988) \\
\hline & & Horn (1988) \\
\hline & & Hornsby and Smith (1995) \\
\hline & & Hutchinson (1984) \\
\hline & & Hutchinson and Brefka (1997) \\
\hline & & Mansfield (1976) \\
\hline & & McNeilly and Barr (1997) \\
\hline & & Schramm and Dortch (1991) \\
\hline & & Spinks and Wells $(1987,1993)$ \\
\hline & & Sulastri et al. (2015) \\
\hline & & Wells et al. (1981) \\
\hline
\end{tabular}




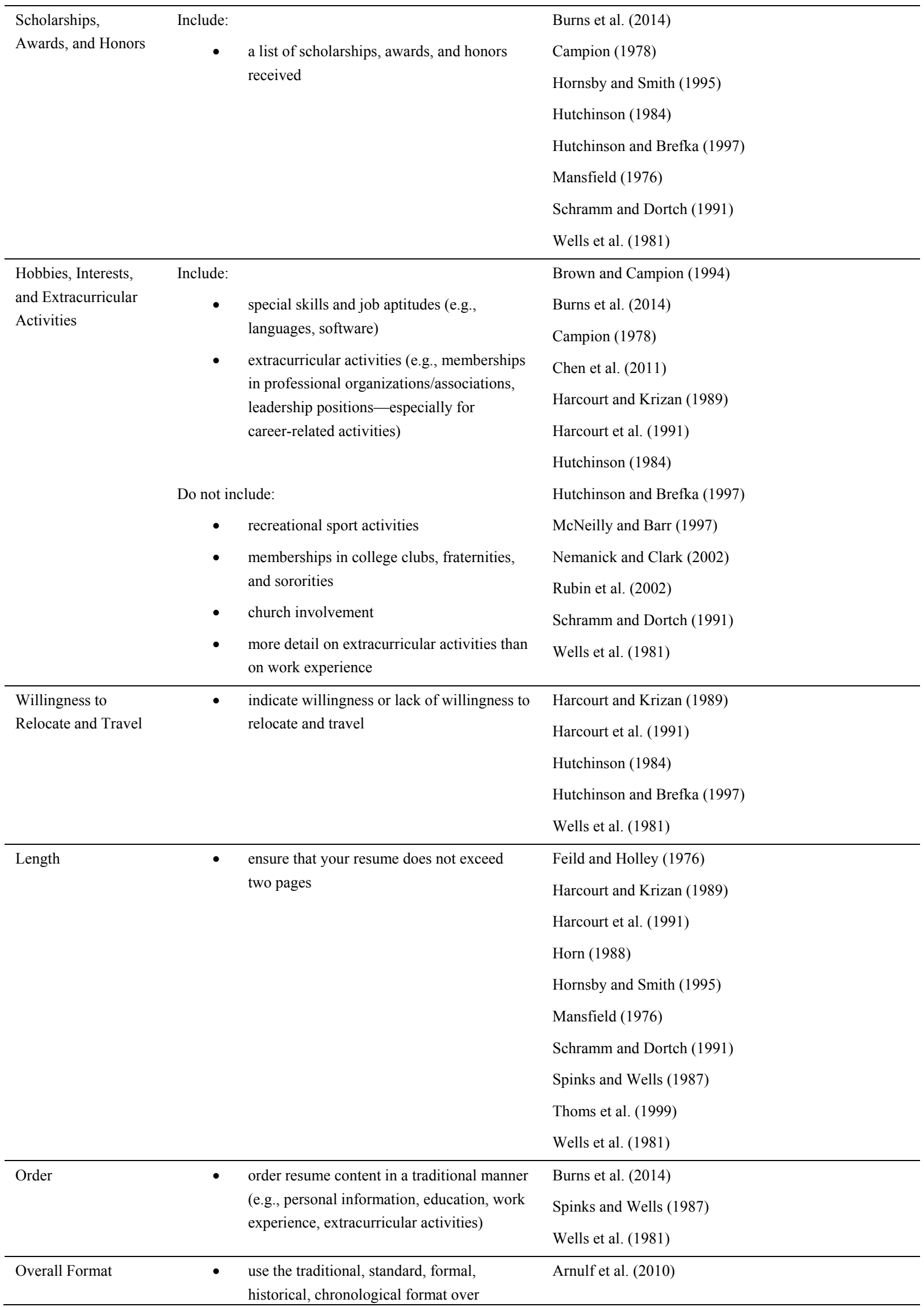


alternative options (e.g., functional, informal, creative, imaginative, web-based, video-based)
Chen et al. (2011)

Hornsby and Smith (1995)

Schramm and Dortch (1991)

Schullery et al. (2009)

Toth (1993)

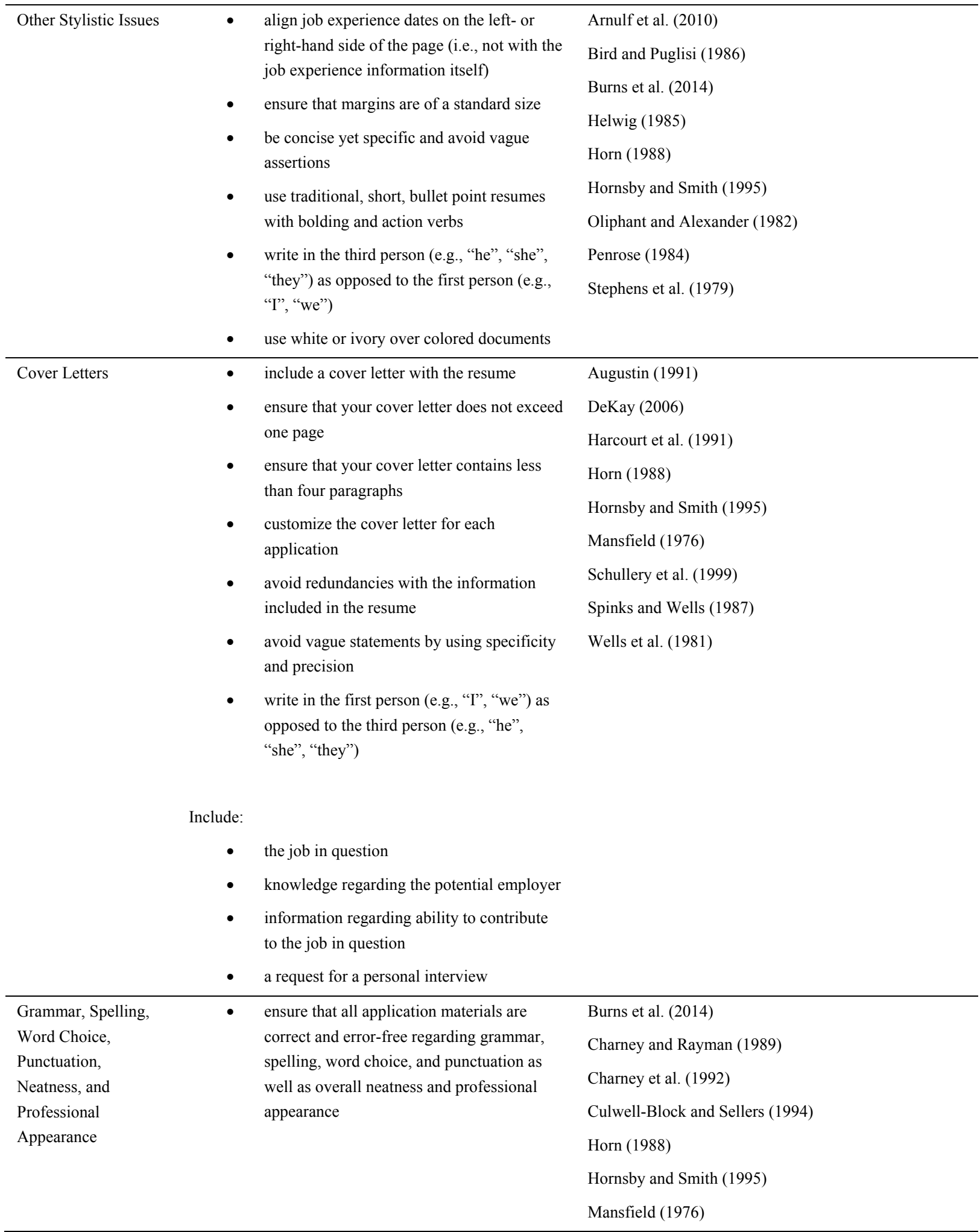


McDowell (1987)

Schramm and Dortch (1991)

Spinks and Wells $(1987,1993)$

Stephens et al. (1979)

Wells et al. (1981)

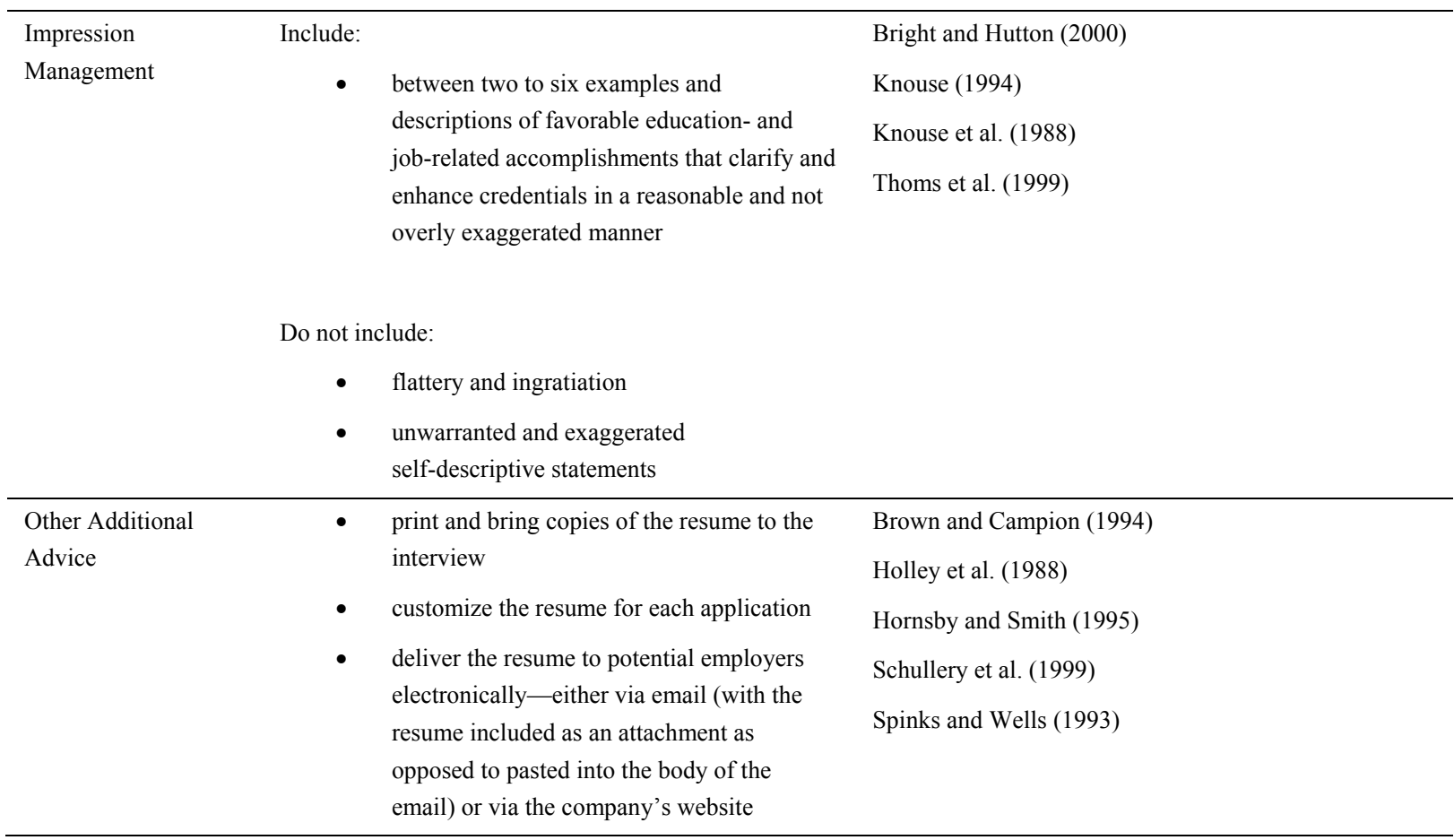

Table 2. Where should we go next? An organizing framework for future research questions

\begin{tabular}{|c|c|}
\hline Area & Future Research Questions \\
\hline \multirow[t]{7}{*}{$\begin{array}{l}\text { What information should be included } \\
\text { in the resume? }\end{array}$} & $\begin{array}{l}\text { Are more professional email addresses more favorably received than less professional email } \\
\text { addresses? }\end{array}$ \\
\hline & $\begin{array}{l}\text { Is a career objective, a job objective, or a combined career and job objective received most } \\
\text { favorably? }\end{array}$ \\
\hline & $\begin{array}{l}\text { Is a summary of qualifications effective if a career objective, a job objective, or a combined career } \\
\text { and job objective has already been included? }\end{array}$ \\
\hline & $\begin{array}{l}\text { Is it most effective to include GPA within major, overall GPA, or both within major and overall } \\
\text { GPA? }\end{array}$ \\
\hline & Is the inclusion of GPA information effective when applicants are applying to non-entry-level jobs? \\
\hline & $\begin{array}{l}\text { Is information regarding the major source of financing during college or university important to } \\
\text { include? }\end{array}$ \\
\hline & Is information regarding class projects and coursework important to include? \\
\hline
\end{tabular}


Are resumes prepared with or without references rated more favorably?

If resumes are prepared without references, then should the verbiage "references available upon request" be included?

Should hobbies and recreational/outside interests be included?

Should extracurricular activities be included in resumes for non-student applicants and non-recent graduate applicants?

Is it more effective to include information regarding willingness to relocate and travel in the resume or in the cover letter?

How long should the resume be?

In what order and style should the resume content be arranged?

What is the best available advice for cover letter writing?

What other advice is there for resume and cover letter writing?
Is the most effective resume page length one page or two pages?

Is a full two-page resume more effective than a one-and-a-half-page resume?

For non-student applicants and non-recent graduate applicants, is it more effective for the work experience section to precede the education section?

Are resumes that include information pertaining to personality, emotional intelligence, diversity tolerance, and preferred organizational structure (Wright et al., 2011) more effective than the traditional resume format?

Is information pertaining to personality, emotional intelligence, diversity tolerance, and preferred organizational structure (Wright et al., 2011) more effective when it is included in the resume or in the cover letter?

Are cover letters written in a paragraph format more effective than cover letters written in a combined paragraph and bullet point format or in a combined paragraph and table format?

What is the appropriate level of assertiveness to include in application materials?

Have the substantial technological advancements changed the way that employers prefer to receive resumes?

Is it more effective to electronically submit resumes in an Adobe PDF file format or in a Word document file format?

Is it more effective to electronically submit a separate resume file and a separate cover letter file or should one file containing both the resume and the cover letter be submitted?

Should the cover letter be pasted into the email itself and the resume attached to the email or should the resume and cover letter be attached to the email and something else be written in the body of the email? 


\subsection{Potential Limitations}

Overall, despite recent claims that "there are no commonly accepted resume items and attributes across jobs and industries" (Su et al., 2015, p. 712), even the focal practical implication of that paper for applicants (which was framed in the context of the hospitality industry and recommended focusing resume content on job-related degree and grade information) is clearly a conclusion that is consonant with the advice from the literature (e.g., Burns et al., 2014; Feild \& Holley, 1976; McNeilly \& Barr, 1997; Schramm \& Dortch, 1991). Regardless, especially as a result of the aforementioned technological and other advancements since many of the research studies cited in the current paper have been conducted, future research should seek to replicate the historical advice regarding resume writing (which was summarized in Table 1) as well as to seek to further advance the resume research literature by beginning to answer the future research questions noted in Table 2 .

An additional potential limitation associated with the current paper is the generalizability of the historical advice summarized. Contrarians may argue that the advice summarized in Table 1 does not generalize to all types of jobs, industries, companies, and geographic locations. Nevertheless, there is reason to believe that this potential limitation may be less concerning than some contrarians may assert. Specifically, no significant differences have been found between the resume and cover letter preferences of smaller and larger organizations (Ray et al., 1994; Spinks \& Wells, 1993). In addition, some research has demonstrated relatively similar results regarding the perceptions of American and Australian personnel professionals when evaluating resumes (e.g., Welch, 1986). More recently, Schullery and colleagues (2009) found that preferences for resumes and cover letters were highly similar across geographic range, company size, and industry.

One final potential limitation associated with the current paper is that many of the studies in the resume literature (and thus, many of the studies summarized and integrated in the current paper) have focused on recent post-secondary graduates as applicants. As noted in various future research questions (see Table 2), it will be beneficial for subsequent studies to assess the generalizability of some of the findings that appear to be targeted predominantly towards current students and recent graduates-for example, should extracurricular activities be included in resumes for non-student applicants and non-recent graduate applicants? For non-student applicants and non-recent graduate applicants, is it more effective for the work experience section to precede the education section?

\subsection{Conclusion}

The current paper has summarized the extant empirical resume research literature that has accumulated over the last several decades in order to provide the most systematic and comprehensive summary to date. The current paper provided a synthesis of the historical empirical research literature through the lens of the advice that has accumulated thus far (Table 1) and also provided an organizing framework containing future research questions that need to be investigated in order to continue moving the literature forward (Table 2). Job applicants can glean advice from the accumulated research evidence, business communication instructors can instruct their students based on this evidence, and researchers now have an organizing framework with numerous future research questions in order to further advance the resume research literature.

\section{References}

Anderson, N. H., \& Barrios, A. A. (1961). Primacy effects in personality impression formation. Journal of Abnormal and Social Psychology, 63, 346-350. https://doi.org/10.1037/h0046719

Arnulf, J., K., Tegner, L., \& Larssen, Ø. (2010). Impression making by resume layout: Its impact on the probability of being shortlisted. European Journal of Work and Organizational Psychology, 19, 221-230. https://oi.org/10.1080/13594320902903613

Augustin, H. M. (1991). The written job search: A comparison of the traditional and a nontraditional approach. Business Communication Quarterly, 54, 13-14. https://doi.org/10.1177/108056999105400304

Bendick, M., Jackson, C. W., \& Romero, J. H. (1996). Employment discrimination against older workers: An experimental study of hiring practices. Journal of Aging \& Social Policy, 8, 25-46. https://doi.org/10.1300/J031v08n04_03

Bertrand, M., \& Mullainathan, S. (2004). Are Emily and Greg more employable than Lakisha and Jamal? A field experiment on labor market discrimination. The American Economic Review, 94, 991-1013. https://doi.org/10.1257/0002828042002561 
Bird, C. P., \& Puglisi, D. D. (1986). Method of resume reproduction and evaluations of employment suitability. The Journal of Business Communication, 23, 31-39. https://doi.org/10.1177/002194368602300303

Blackburn-Brockman, E., \& Belanger, K. (2001). One page or two?: A national study of CPA recruiters' preferences for resume length. The Journal of Business Communication, 38, 29-57. https://doi.org/10.1177/002194360103800104

Bright, J. E. H., \& Hutton, S. (2000). The impact of competency statements on resumes for short-listing decisions. International Journal of Selection and Assessment, 8, 41-53. https://doi.org/10.1111/1468-2389.00132

Brown, B. K., \& Campion, M. A. (1994). Biodata phenomenology: Recruiters' perceptions and use of biographical information in resume screening. Journal of Applied Psychology, 79, 897-908. https://doi.org/10.1037/0021-9010.79.6.897

Burns, G. N., Christiansen, N. D., Morris, M. B., Periard, D. A., \& Coaster, J. A. (2014). Effects of applicant personality on resume evaluations. Journal of Business and Psychology, 29, 573-591. https://doi.org/10.1007/s10869-014-9349-6

Campion, M. A. (1978). Identification of variables most influential in determining interviewers' evaluations of applicants in a college placement center. Psychological Reports, 42, 947-952. https://doi.org/10.2466/pr0.1978.42.3.947

Catano, V. M., Wiesner, W. H., \& Hackett, R. D. (2016). Recruitment and selection in Canada (6th ed.). Toronto, ON: Nelson Education Ltd.

Charney, D. H., \& Rayman, J. R. (1989). The role of writing quality in effective student resumes. Journal of Business and Technical Communication, 3, 36-53. https://doi.org/10.1177/105065198900300102

Charney, D. H., Rayman, J., \& Ferreira-Buckley, L. (1992). How writing quality influences readers' judgments of resumes in business and engineering. Journal of Business and Technical Communication, 6, 38-74. https://doi.org/10.1177/1050651992006001002

Chen, C., Huang, Y., \& Lee, M. (2011). Test of a model linking applicant resume information and hiring recommendations. International Journal of Selection and Assessment, 19, 374-387. https://doi.org/10.1111/j.1468-2389.2011.00566.x

Cole, M. S., Rubin, R. S., Feild, H. S., \& Giles, W. F. (2007). Recruiters' perceptions and use of applicant resume information: Screening the recent graduate. Applied Psychology: An International Review, 56, 319-343. https://doi.org/10.1111/j.1464-0597.2007.00288.x

Culwell-Block, B., \& Sellers, J. A. (1994). Resume content and format-Do the authorities agree? Business Communication Quarterly, 57, 27-30. https://doi.org/10.1177/108056999405700405

DeKay, S. H. (2006). Expressing emotion in electronic job cover letters. Business Communication Quarterly, 69, 435-439. https://doi.org/10.1177/108056990606900419

Derous, E., \& Ryan, A. M. (2012). Documenting the adverse impact of resume screening: Degree of ethnic identification matters. International Journal of Selection and Assessment, 20, 464-474. https://doi.org/10.1111/ijsa.12009

Dipboye, R. L., Arvey, R. D., \& Terpstra, D. E. (1977). Sex and physical attractiveness of raters and applicants as determinants of resume evaluations. Journal of Applied Psychology, 62, 288-294. https://doi.org/10.1037/0021-9010.62.3.288

Dipboye, R. L., Fromkin, H. L., \& Wiback, K. (1975). Relative importance of applicant sex, attractiveness, and scholastic standing in evaluation of job applicant resumes. Journal of Applied Psychology, 60, 39-43. https://doi.org/10.1037/h0076352

Dittman, N. A. (1983). Job winning resumes. Business Communication Quarterly, 46, 16-22. https://doi.org/10.1177/108056998304600204

Erez, A., \& Grant, A. M. (2014). Separating data from intuition: Bringing evidence into the management classroom. Academy of Management Learning \& Education, 13, 104-119. https://doi.org/10.5465/amle.2013.0098 
Feild, H. S., \& Holley, W. H. (1976). Resume preparation: An empirical study of personnel managers' $\begin{array}{lllll}\text { perceptions. } & \text { Vocational 229-237. }\end{array}$ https://doi.org/10.1002/j.2164-585X.1976.tb00925.x

Hakel, M. D., Dobmeyer, T. W., \& Dunnette, M. D. (1970). Relative importance of three content dimensions in overall suitability ratings of job applicants' resumes. Journal of Applied Psychology, 54, 65-71. https://doi.org/10.1037/h0028649

Harcourt, J., \& Krizan, A. C. B. (1989). A comparison of resume content preferences of Fortune 500 personnel administrators and business communication instructors. The Journal of Business Communication, 26, 177-190. https://doi.org/10.1177/002194368902600206

Harcourt, J., Krizan, A. C. B., \& Merrier, P. (1991). Recruiters' opinions about resume content. Journal of Education for Business, 66, 267-273. https://doi.org/10.1080/08832323.1991.10117483

Helwig, A. A. (1985). Corporate recruiter preferences for three resume styles. Vocational Guidance Quarterly, 34, 99-105. https://doi.org/10.1002/j.2164-585X.1985.tb01109.x

Hiemstra, A. M. F., Derous, E., Serlie, A. W., \& Born, M. P. (2012). Fariness perceptions of video resumes among ethnically diverse applicants. International Journal of Selection and Assessment, 20, 423-433. https://doi.org/10.1111/ijsa.12005

Holley, W. H., Higgins, E., \& Speights, S. (1988). Resumes and cover letters: What do HR managers really want? Personnel, 65, 49-51.

Horn, J. K. (1988). What employers want in cover letters and resumes. Journal of Education for Business, 64, 90-93. https://doi.org/10.1080/08832323.1988.10117336

Hornsby, J. S., \& Smith, B. N. (1995). Resume content: What should be included and excluded. S.A.M. Advanced Management Journal, 60, 4-9.

Hutchinson, K. L. (1984). Personnel administrators' preferences for resume content: A survey and review of empirically based conclusions. The Journal of Business Communication, 21, 5-14. https://doi.org/10.1177/002194368402100401

Hutchinson, K. L., \& Brefka, D. S. (1997). Personnel administrators' preferences for resume content: Ten years after. Business Communication Quarterly, 60, 67-75. https://doi.org/10.1177/108056999706000206

Knouse, S. B. (1989). The role of attribution theory in personnel employment selection: A review of the recent literature. Journal of General Psychology, 116, 183-196. https://doi.org/10.1080/00221309.1989.9711122

Knouse, S. B. (1994). Impressions of the resume: The effects of applicant education, experience, and impression management. Journal of Business and Psychology, 9, 33-45. https://doi.org/10.1007/BF02230985

Knouse, S. B., Giacalone, R. A., \& Pollard, H. (1988). Impression management in the resume and its cover letter. Journal of Business and Psychology, 3, 242-249. https://doi.org/10.1007/BF01014492

Mansfield, C. E. (1976). We hear you Mr./Ms. business ... The resume and cover letter. Business Communication Quarterly, 39, 20-22. https://doi.org/10.1177/108056997603900308

Marlowe, C. M., Schneider, S. L., \& Nelson, C. E. (1996). Gender and attractiveness biases in hiring decisions: Are more experienced managers less biased? Journal of Applied Psychology, 81, 11-21. https://doi.org/10.1037/0021-9010.81.1.11

McDowell, E. E. (1987). Perceptions of the ideal cover letter and ideal resume. Journal of Technical Writing and Communication, 17, 179-191. https://doi.org/10.2190/BK23-74U3-333Q-0T86

McIntyre, S., Moberg, D. J., \& Posner, B. Z. (1980). Preferential treatment in preselection decisions according to sex and race. Academy of Management Journal, 23, 738-749. https://doi.org/10.2307/255560

McNeilly, K. M., \& Barr, T. F. (1997). Convincing the recruiter: A comparison of resume formats. Journal of Education for Business, 72, 359-363. https://doi.org/10.1080/08832323.1997.10116871

Muchinsky, P. M., \& Harris, S. L. (1977). The effect of applicant sex and scholastic standing on the evaluation of job applicant resumes in sex-typed occupations. Journal of Vocational Behavior, 11, 95-108. https://doi.org/10.1016/0001-8791(77)90020-3 
Nemanick, R. C. Jr., \& Clark, E. M. (2002). The differential effects of extracurricular activities on attributions in resume evaluation. International Journal of Selection and Assessment, 10, 206-217. https://doi.org/10.1111/1468-2389.00210

Oliphant, V. N., \& Alexander, E. R. III. (1982). Reactions to resumes as a function of resume determinateness, applicant characteristics, and sex of raters. Personnel Psychology, 35, 829-842. https://doi.org/10.1111/j.1744-6570.1982.tb02225.x

Penrose, J. M. (1973). Does order make a difference in resumes? The Journal of Business Communication, 10, 15-19. https://doi.org/10.1177/002194367301000303

Penrose, J. M. (1984). A discrepancy analysis of the job-getting process and a study of resume techniques. The Journal of Business Communication, 21, 5-15. https://doi.org/10.1177/002194368402100301

Pibal, D. C. (1985). Criteria for effective resumes as perceived by personnel directors. Personnel Administrator, 30, 119-123.

Ray, C. M., Stallard, J. J., \& Hunt, C. S. (1994). Criteria for business graduates' employment: Human resource managers' perceptions. Journal of Education for Business, 69, 140-144. https://doi.org/10.1080/08832323.1994.10117672

Renwick, P. A., \& Tosi, H. (1978). The effects of sex, marital status, and educational background on selection decisions. Academy of Management Journal, 21, 93-103. https://doi.org/10.2307/255665

Roderick, J. C., \& Jelley, H. M. (1992). An innovative method for teaching resume design. Business Communication Quarterly, 55, 1-4. https://doi.org/10.1177/108056999205500201

Rubin, R. S., Bommer, W. H., \& Baldwin, T. T. (2002). Using extracurricular activity as an indicator of interpersonal skill: Prudent evaluation of recruiting malpractice? Human Resource Management, 41, 441-454. https://doi.org/10.1002/hrm.10053

Schlenker, B. R. (1980). Impression management. Monterey, CA: Brooks/Cole.

Schramm, R. M., \& Dortch, R. N. (1991). An analysis of effective resume content, format, and appearance based on college recruiter perceptions. Business Communication Quarterly, 54, 18-23. https://doi.org/10.1177/108056999105400306

Schullery, N. M., Ickes, L., \& Schullery, S. E. (2009). Employer preferences for resumes and cover letters. Business Communication Quarterly, 72, 163-176. https://doi.org/10.1177/1080569909334015

Spinks, N., \& Wells, B. (1987). Letters of application and resumes: A comparison of corporate views. Business Communication Quarterly, 50, 9-16. https://doi.org/10.1177/108056998705000303

Spinks, N., \& Wells, B. (1993). Are preferences of small companies likely to agree with those of large corporations concerning resumes and application letters? Business Communication Quarterly, 56, 28-29. https://doi.org/10.1177/108056999305600307

Stanley-Weigand, P. (1991). Organizing the writing of your resume. Business Communication Quarterly, 54, 11-12. https://doi.org/10.1177/108056999105400303

Stephens, D. B., Watt, J. T., \& Hobbs, W. S. (1979). Getting through the resume preparation maze: Some empirically based guidelines for resume format. Vocational Guidance Quarterly, 28, 25-34. https://doi.org/10.1002/j.2164-585X.1979.tb00080.x

Stull, J. (1978). Self-awareness, self-esteem, and resume writing: An exercise. Business Communication Quarterly, 41, 8-10. https://doi.org/10.1177/108056997804100403

Su, C., Lorgnier, N. G. A., Yang, J., \& Oh, A. H. (2015). How does the interview change the importance of resume information in acceptance decisions? An experimental study in the hotel industry. Service Business, 9, 711-732. https://doi.org/10.1007/s11628-014-0253-y

Sulastri, A., Handoko, M., \& Janssens, J. M. A. M. (2015). Grade point average and biographical data in personal resumes: Predictors of finding employment. International Journal of Adolescence and Youth, 20, 306-316. https://doi.org/10.1080/02673843.2014.996236

Thoms, P., McMasters, R., Roberts, M. R., \& Dombkowski, D. A. (1999). Resume characteristics as predictors of an invitation to interview. Journal of Business and Psychology, 13, 339-356. https://doi.org/10.1023/A:1022974232557 
Toth, C. (1993). Effect of resume format on applicant selection for job interviews. Applied H.R.M. Research, 4, $115-125$.

Waung, M., Hymes, R. W., \& Beatty, J. E. (2014). The effects of video and paper resumes on assessments of personality, applied social skills, mental capability, and resume outcomes. Basic and Applied Social Psychology, 36, 238-251. https://doi.org/10.1080/01973533.2014.894477

Waung, M., Hymes, R., Beatty, J. E., \& McAuslan, P. (2015). Self-promotion statements in video resumes: Frequency, intensity, and gender effects on job applicant evaluation. International Journal of Selection and Assessment, 23, 345-360. https://doi.org/10.1111/ijsa.12119

Weeks, F. W. (1975). Data sheets and resumes. Business Communication Quarterly, 38, 13-14. https://doi.org/10.1177/108056997503800405

Welch, D. (1986). The components of an effective job resume. Asia Pacific Journal of Human Resources, 24, 18-20. https://doi.org/10.1177/103841118602400408

Wells, B., Spinks, N., \& Hargrave, J. (1981). A survey of the chief personnel officers in the 500 largest corporations in the United States to determine their preferences in job application letters and personal resumes. Business Communication Quarterly, 44, 3-7. https://doi.org/10.1177/108056998104400202

Wright, E. W., Domagalski, T. A., \& Collins, R. (2011). Improving employee selection with a revised resume format. Business Communication Quarterly, 74, 272-286. https://doi.org/10.1177/1080569911413809

\section{Copyrights}

Copyright for this article is retained by the author(s), with first publication rights granted to the journal.

This is an open-access article distributed under the terms and conditions of the Creative Commons Attribution license (http://creativecommons.org/licenses/by/4.0/). 